\title{
LA ARQUEOLOGÍA BÍBLICA: UNA CIENCIA HERMENÉUTICA ENTRE HISTORIA Y TOLDOT
}

\author{
Stéphane Vinolo ${ }^{1}$
}

\section{RESUMEN}

La arqueología bíblica es sin duda una ciencia cuyas implicaciones políticas son fundamentales. Al querer esta establecer el estatuto histórico del texto bíblico, se encuentra en el centro de muchos debates académicos desde su surgimiento hasta hoy en día. Sin embargo, mostramos aquí que el carácter histórico del relato bíblico se debe recontextualizar dentro de varios significados posibles de la palabra Historia. Si bien las tradiciones griegas y romanas vinculan el concepto de historia con la verdad, el mundo hebreo, pensando a la Historia como toldot, la vincula con el sentido. Esta diferencia entre verdad y sentido dentro del concepto de Historia nos permite cuestionar los límites de la arqueología bíblica y establecer lo que podemos razonablemente esperar de esta.
Palabras clave: arqueología bíblica, Historia, sentido, Toldot, verdad.

\section{ABSTRACT}

From its early beginnings, biblical archaeology has suffered from political use and abuse. By questioning or establishing the historical reality of biblical characters and events, it is still today at the centre of several academic debates. It is demonstrated here that most of the misunderstandings of these debates lie in a confusion of what History means. Even though we know that in the ancient Greek and Roman worlds, the concept of historia was strongly linked with the one of truth, in the Hebraic and biblical worlds the concept of toldot was related to the ones of sense and meaning. This difference between truth and sense within the concept of History helps us establish the scope and limits of biblical

1 Pontificia Universidad Católica del Ecuador, Facultad Eclesiástica de Ciencias Filosófico-Teológicas, Quito, Ecuador (svinolo@puce.edu.ec). 
archaeology, precising what is to be expected from it.

La arqueología bíblica presenta en su mismo nombre una paradoja que hace de esta una ciencia aparte, o como mínimo, una disciplina cuyas fronteras siempre amenazan extenderse más allá de lo que la epistemología autoriza. Efectivamente, podemos preguntarnos: ¿por qué los arqueólogos investigando yacimientos cuyos nombres hacen referencia a espacios geográficos mencionados en la Biblia necesitan precisar de manera explícita que hacen arqueología específicamente bíblica, ya que por ejemplo ningún arqueólogo especialista de Grecia o del Imperio romano siente la necesidad de precisar que hace arqueología en referencia a la Historia de la guerra del Peloponeso de Tucídides (Tucídides, 2005) o a la Historia de Roma de Polibio (Polibio, 2008)? La simple existencia de una disciplina que precisa su carácter bíblico cuestiona la especificidad de esta, ya que los arqueólogos cuyas investigaciones se desarrollan en el campo histórico de la antigüedad griega o romana hacen simplemente arqueología, sin más precisión. No podemos dejar de notar entonces que la Biblia no se considera como cualquier otro libro a la hora de hacer arqueología por el simple hecho
Key words: biblical archaeology, History, sense, Toldot, truth.

que se precisa que se hace arqueología específicamente bíblica. Si bien la arqueología bíblica se somete a muchos de los criterios científicos de la arqueología y respeta en gran parte su epistemología, podemos sospechar que la Biblia pesa de forma muy fuerte sobre las interpretaciones que los arqueólogos hacen de sus descubrimientos ya sea de forma positiva o de forma negativa. Nuestra sospecha se puede fundamentar en hechos académicos muy simples que revelan cierto malestar académico frente a la arqueología bíblica. Podemos notar, por ejemplo, que en el ámbito universitario, la revista académica The Biblical Archaeologist, creada por G. Ernest Wright y publicada entre los años 1938 y 1997 cambió su nombre a Near Eastern Archaeology en 1998 para evitar esas acusaciones y mantenerse de manera estricta en el campo de la investigación científica.

Debemos sin embargo notar que existen dos actitudes muy diferentes o dos usos muy distintos, que los arqueólogos pueden hacer de la Biblia, lo que nos llevaría a presentar dos concepciones muy diferentes de la arqueología bí-

\footnotetext{
${ }^{2}$ http://www.asor.org/pubs/nea/ [Consultado el 15 de febrero 2016, 21h38]
} 
blica. Podemos imaginar una visión minimalista de la arqueología bíblica. Esta visión conocida como "Escuela de Copenhague", ya que dos de sus mayores representantes -Niels Peter Lemche y Thomas L. Thompson- eran académicos en la universidad de Copenhague, defiende la idea según la cual la Biblia relata los mitos fundadores de varias religiones monoteístas, pero que en muy pocos casos estos mitos se pueden corroborar con evidencias arqueológicas para pasar del estatuto de mito al de Historia. Al contrario, existe la posición maximalista que consiste en afirmar el carácter sumamente histórico de la Biblia ${ }^{3}$ apoyándose sobre los descubrimientos que parecen confirmar lo que relata la Biblia. Este debate entre las dos posiciones no fuera tan complicado ni tan vigoroso si la arqueología no fuera una ciencia profundamente hermenéutica. Si bien es verdad que toda ciencia conlleva cierta hermenéutica, ya que no existen hechos de por sí, y que cada hecho debe ser establecido (por no decir construido) mediante un proceso interpretativo que le da sentido dentro de una teoría general o de un paradigma global (Kuhn, 1962), es aún más perceptible en lo que se refiere a la arqueología ya que cada rastro de civilizaciones pasadas puede ser interpretado de manera radicalmente diferente dependiendo del paradigma dentro del cual se decida interpretarlo y darle sentido.

Más aún, la complejidad del debate alrededor de la arqueología bíblica proviene del hecho de que el paradigma dentro del cual los arqueólogos maximalistas interpretan los datos arqueológicos es un paradigma absoluto ya que se basa en una fe que no puede ser cuestionada - en cuanto es una fe - desde un punto de vista científico. Si este debate surgiera entre dos paradigmas científicos, estaríamos en una situación epistemológica común en la cual varios paradigmas luchan por imponerse, tal como podemos verlo por ejemplo en el caso del debate entre el paradigma corpuscular de la luz y el paradigma ondulatorio de esta. Sin embargo, este no es el caso en la arqueología bíblica a la hora de determinar cuál de la interpretación maximalista o minimalista es la correcta. Para la separación radical, que yace entre las dos órdenes que son la ciencia y la fe, ninguna ciencia refutará jamás la fe, y toda fe que espera razones científicas para creer es una mala $\mathrm{fe}^{4}$. Si bien los paradigmas científicos se refutan los unos a los otros de manera bastante fácil y consensual, y que hemos podido pasar en física del paradigma newtoniano al paradigma de la física de Einstein, estos saltos de paradigmas son mucho más complicados en lo que se re-

\footnotetext{
${ }^{3}$ Para ver una oposición concreta de estas dos posiciones sobre el caso específico del tamaño de la Jerusalén antigua, podremos leer el artículo de Tuland (Tuland, 1967).

${ }^{4}$ Para la separación radical de la fe y de la razón, y de la separación de las órdenes, podremos leer las obras de Blaise Pascal y particularmente su éxtasis místico del 23 de noviembre 1654, conocido como el Memorial.
} 
fiere a la arqueología bíblica ya que el carácter sagrado (y por lo tanto absoluto) del paradigma bíblico permite e impone un uso político ${ }^{5}$ de la arqueología y una línea de interpretación para algunos incuestionable.

Quisiéramos entonces preguntarnos aquí en este trabajo lo que se puede esperar de la arqueología bíblica y los límites de dicha ciencia localizándola entre Historia y mitología. Pero notemos de inmediato que el establecer límites a un campo disciplinario no es querer destruirlo ni minimizarlo, sino al contrario cercarlo con fronteras dentro de las cuales podemos apreciar el despliegue de toda su fuerza científica.

\section{¿QUÉ ME ESTÁ PERMITIDO ESPERAR?}

Sin duda alguna, la arqueología bíblica presenta elementos cuyos descubrimientos concuerdan perfectamente con los que nos relatan los textos bíblicos, o como mínimo presentan una adecuación tan probable que fácilmente entendemos en qué medida algunos arqueólogos fueron tentados por la interpretación maximalista de la arqueología bíblica. Para tomar un ejemplo históricamente muy lejano, podemos pensar aquí en el relato del diluvio tal como aparece en el Antiguo Testamento. En diversas excavaciones realizadas en las ciudades de Ur, Uruk, pero también de Shuruppak, Nuppur o Lagash, Sir Leonard Wooley, a finales de los años 1920, se encontró una capa de rastros que evidencia la presencia de una civilización (que data del 3000 al $2500 \mathrm{aC}$ ) por debajo de una capa de lodo de dos metros y medio de profundidad. Al extenderse esta capa de lodo sobre varios kilómetros, esto podría dejarnos pensar que estas civilizaciones fueron sumergidas de forma rápida y casi homogénea por un gran flujo de agua y lodo que les sorprendió al llegar a ellos de manera muy rápida y masiva (Wooley, 1929). A raíz de este hecho geológico incontrastable, algunos arqueólogos interpretaron esto como una posible prueba de la realidad del diluvio tal como nos los cuenta la Biblia. Tendríamos aquí, con estas excavaciones, una adecuación perfecta entre la arqueología y la Biblia. Sin embargo, bien vemos el papel que la interpretación juega en este caso, y podemos entender cómo la interpretación minimalista y maximalista se oponen en el caso de la arqueología bíblica. Para quien quisiera proponer una interpretación mini-

\footnotetext{
${ }^{5}$ No afirmamos aquí que el uso político de la arqueología es el triste privilegio de la arqueología bíblica, ya que por ejemplo el caso de las falsificaciones del yacimiento de Iruña-Veleia en el País Vasco español nos lleva a pensar que toda arqueología es política. Sin embargo, tal vez la arqueología bíblica sea el campo de la arqueología en el cual el uso político de los datos aparece de la manera más fuerte y evidente.
} 
malista del relato bíblico, se podría al contrario hacer del diluvio una simple estructura antropológica, ya que muchas culturas, incluso muchas para las cuales no disponemos de ningún rastro arqueológico que nos deje pensar en la realidad de un diluvio, presentan elementos vinculados a diluvios y grandes inundaciones en sus mitologías. De la misma manera que muchas mitologías presentan dioses que salen de las aguas o Dioses que bajan del cielo, podríamos pensar que la destrucción por el agua es una estructura antropológica fundamental de las sociedades humanas ${ }^{6}$. Recordemos aquí que la mitología incaica presenta un diluvio generado por el dios Viracocha, que la mitología de la religión Mexica dispone de una diosa -Chalchiuhtlicue- del agua que también generó un diluvio. Podríamos encontrar de la misma manera diluvios en las mitologías Pascuense o Kawésqar, es decir en regiones muy alejadas de la región en la cual se redactó la Biblia. Salvo que pensemos en la coexistencia de diluvios en todos los espacios geográficos del planeta, podemos cuestionar el simple hecho que busquemos un vínculo entre el relato bíblico del diluvio y un diluvio real. Al contrario, en una visión estructuralista de los textos y de los colectivos humanos podríamos al contrario evidenciar que por el vínculo fundamental y evidente que tiene el agua con la vida, la generación y la producción ${ }^{7}$, podemos imaginar que también haya sido vinculada por simple razones antropológicas, con la muerte y la destrucción. Sería fácil entonces imaginar que la destrucción por el agua es un elemento mitológico más que histórico (Girard, 2008) ya que parece ser una estructura mitológica casi universal o, por lo menos, que aparece en muchas regiones del planeta y en culturas muy diversas.

Sin embargo, si tal posición se puede defender para algunos puntos como el del diluvio bíblico, la arqueología bíblica presenta elementos que no podemos dejar de vincular con el relato bíblico y simplemente rechazar en estructuras antropológicas fundamentales. Si bien hemos visto que el diluvio es un tema demasiado genérico en la mitología para afirmar de manera segura la adecuación del relato bíblico con los rastros arqueológicos, otros elementos arqueológicos evidencian un vínculo muy fuerte con el relato bíblico. Este es el caso por ejemplo del descubrimiento hecho por la arqueóloga Eilat Mazar de la Universidad Hebrea de Jerusalén (Mazar, 2008) que pretende haber descubierto el túnel (conocido como "tsinnor") con el cual el Rey David pudo conquistar a Jerusalén, túnel mencio-

\footnotetext{
${ }^{6}$ Dentro de este paradigma estructuralista fundamental podremos ver las obras de Claude Levi-Strauss. Todas las interpretaciones estructurales de mitos por Lévi-Strauss han sido reunidas en los cuatro volúmenes de Mythologiques (Lévi-Strauss, 2009).

${ }^{7}$ Ya sea de manera biológica o agrícola.
} 
nado en el segundo libro del profeta Samuel (cf., 2 Samuel, 5, 6-8). En este caso, incluso los que hacen arqueología bíblica según la posición minimalista, bien deben acordar que el túnel parece exactamente mencionado en la Biblia y que la interpretación minimalista se encuentra frente a una verdadera dificultad a la hora de darle otro sentido que su sentido bíblico. De la misma manera, algunos piensan que el túnel supuestamente creado por Ezequías fue encontrado y permite entender cómo la ciudad de Jerusalén se abasteció de agua potable mientras las tropas de Asiria, dirigidas por el rey Senaquerib, avanzaban sobre ella después de haber destrozado a varias otras ciudades. Este túnel, que lleva agua desde la fuente del Gijón hasta la piscina de Siloé, presenta rastros muy precisos como la inscripción de Siloé que nos permite incluso entender el porqué el túnel no está cavado de manera recta sino sinusoidal ya que los obreros que lo excavaron se guiaban con el sonido que hacía cada equipo a cada lado de la excavación (Sneh et al., 2008). Una vez más en este caso, parece que la arqueología confirma de forma muy precisa los relatos bíblicos ${ }^{8}$.
Esta adecuación que parece darle toda su legitimidad a la lectura maximalista de la arqueología bíblica no se limita al Antiguo Testamento. Este es también el caso para el Nuevo Testamento y de manera paradigmática para la Pasión de Cristo. La arqueología bíblica parece revelarnos con una gran precisión los tres últimos días de la vida de Cristo. De esta manera, no solo Cristo aparece obviamente en los manuscritos cristianos, sino además en algunos manuscritos no-cristianos 9 , pero sobre todo, muchos rastros arqueológicos de los cuales disponemos hoy en día parecen estar en adecuación con el relato bíblico de sus últimos días. Así por ejemplo, existe en el British Museum de Londres, bajo la referencia British Museum Syriac MS additional 14.658, una carta redactada en asirio en la cual un nombrado Mara Bar Serapion ${ }^{10}$ le dice a su hijo que debe absolutamente seguir con su camino hacia la sabiduría ya que todos los que se han hecho culpables de maltratar y perseguir a los sabios conocieron un destino funesto ya que sus imperios cayeron los unos tras los otros. Para darle ejemplos a su hijo de este vínculo entre maltrato de los sabios y caída

\footnotetext{
${ }^{8}$ Cf., 2 Crónicas, 32, 30: Ezequías fue también quién cegó la salida superior de las aguas del Guijón y las desvió por un canal subterráneo hacia la parte occidental de la ciudad de David."

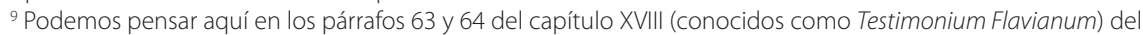
libro Antiquitates ludaicae escrito por Flavio Josefo en los cuales aparece de forma explícita el nombre de Jesús de Nazaret (Josefo, 1997).

${ }^{10}$ Dada la importancia de la mención de la crucifixión de Cristo fuera de la literatura cristina, los estudios acerca de esta carta son muy numerosos. El lector podrá ver por ejemplo el artículo completo de Annette Merz y Teun Tieleman (Merz, Tieleman, 2008).
} 
de los imperios, Mara Bar Serapion toma entonces en esta carta los ejemplos de la muerte de Sócrates que precipitó la caída de Atenas, la de Pitágoras y de los habitantes de Samos, y sobre todo y por fin el ejemplo de los judíos y de la muerte de Cristo. Así tenemos testimonios de la existencia de Cristo no solo en el mundo cristiano -lo que podría parecer sospechoso o lo que podría ser interpretado como una manera de afirmar la verdad del cristianismo dentro del mismo cristianismo, lo que epistemológicamente no nos permitiría afirmar dicha existencia histórica- sino además fuera de él, lo que apoya de manera muy fuerte su probable existencia histórica (Van Voorst, 2000). Pero más allá de textos, la arqueología también nos provee rastros arquitecturales que podrían confirmar la existencia histórica de Cristo y de cierta parte del relato del Nuevo Tes- tamento. Desde 1968, el Padre italiano Virgilio Corbo estuvo excavando por debajo de una pequeña iglesia bizantina octogonal y descubrió lo que podría ser la casa de Pedro ya que encontró inscripciones cristianas que manifiestan la presencia de lo que podríamos pensar hoy como el cristianismo primitivo (Corbo, 1968). Así, algunos puntos que nos revela la arqueología bíblica nos permiten sospechar que muchos de los relatos de la Biblia tienen algún fundamento histórico, ya que la descripción de muchas guerras, de invasiones pero también de ciudades y lugares corresponden con los datos que nos proporciona la arqueología. Gracias a estos casos innegables, los intérpretes maximalistas podrían encontrar los fundamentos epistemológicos de su maximalismo así como cierta legitimidad de este.

\section{LOS DIVINOS LÍMITES DE LA ARQUEOLOGÍA BÍBLICA}

Sin embargo, en cierto sentido que vamos a precisar, sería un error el pensar que la Biblia es un libro de historia, y sería un error aún más grande el querer basar su fe en lo que la arqueología bíblica nos pueda revelar. Podemos entonces cuestionar los fundamentos del paradigma maximalista en arqueología bíblica. Primero porque bien vemos que la arqueología bíblica, por ser una ciencia sumamente hermenéutica, presenta un límite epistemológico. Si bien la existencia de muchos lugares y eventos descritos por la Biblia está confirmada por la arqueología, un problema epistemológico muy profundo surge a la hora de determinar la existencia de individuos en concreto, y peor aún a la hora de determinar si el sentido histórico de estos individuos se encuentra reflejado en el sentido que la Biblia les da. Podemos fácilmente ilustrar esta dificultad epistemológica con ejemplos lejanos a la arqueología bíblica. Podemos 
ver que el Moscú descrito por Dostoievski en sus obras es casi perfecto: su ambiente histórico es exactamente el que describen las novelas de Dostoievski. Los lugares están muy bien descritos, las tiendas están ubicadas tal como los estipulan los textos, y los monumentos históricos reflejan a la perfección la ciudad rusa. Más aún, todos los conflictos evocados por Dostoievski, los juegos políticos y sociales son elementos que se dieron históricamente. Sin embargo, a pesar de estas precisiones, a pesar de que podamos encontrar en Moscú lo esencial del marco que Dostoievski no da a ver en sus obras, nadie podría mostrar, ni nadie pensaría seriamente que los personajes de Dostoievski que se desempeñen dentro de este marco histórico existieron. Así, el mostrar la adecuación intra-textual y extra-textual de un marco dentro del cual están situadas las acciones de un texto no basta para garantizar la existencia de los personajes de esta acción. Pero más allá del problema entre los personajes y el marco dentro del cual se desenvuelven, el problema puede ser extendido al sentido de existencia de los mismos personajes. Podemos perfectamente imaginar que rastros arqueológicos nos demestren la existencia de algún personaje histórico sin que este tenga el sentido que le da cierto texto. Conocemos muchos casos de esta divergencia entre verdad histórica y sentido intra-textual de un personaje en el campo de la filosofía. Es así el caso de todos los personajes creados por Platón: Sócrates, Alcibíades, Gorgas o Protágoras. Sabemos por la arqueología, así como por fuentes textuales, que cada uno de ellos existió históricamente, y dado que varios de ellos ocuparon un papel histórico de gran importancia en Grecia, disponemos de muchas fuentes para corroborar su existencia y entender quiénes fueron. Hay así una realidad histórica innegable de cada uno de ellos. Sin embargo, también sabemos gracias a estudios precisos realizados a lo largo del siglo XX, que sus existencias históricas están muy lejos de la manera de la cual Platón los presenta y los utiliza. Así, Gregory Vlastos (Vlastos, 1991) pudo mostrar que el Sócrates de Platón no es el Sócrates histórico, aunque Sócrates haya existido. De la misma manera, la gran helenista Jacqueline de Romilly (Romilly, 1995) mostró que el Alcibíades histórico no es el Alcibíades tal como lo presenta Platón. Este trabajo y este análisis se podrían realizar para cada uno de los personajes de Platón ya que al no ser un historiador, Platón no pretende presentar a sus personajes de manera histórica, sino dándoles el sentido que permite explicar el triunfo de Sócrates en cada uno de los diálogos, y presentar una oposición filosófica radical entre ellos y Sócrates. Hay así una ruptura hermenéutica entre lo intra-textual y lo extra-textual, a pesar que puedan tener un referente común. 
Podemos entonces concluir con dos afirmaciones de estas reflexiones en lo que se refiere a las diferentes posiciones intelectuales en arqueología bíblica. Primero, el hecho que la arqueología bíblica confirme la existencia histórica del marco en el cual se desempeñan los personajes de la Biblia no nos permite deducir la existencia histórica de estos personajes. Segundo, aunque se pueda llegar a demostrar la existencia histórica de los personajes de la Biblia, en ningún caso esto demostraría que el sentido histórico que tuvieron es el sentido que la Biblia describe o que la Biblia les da. Para utilizar el vocabulario creado por Deleuze (Deleuze \& Guattari, 1991, 60-81), podemos decir que la arqueología bíblica podrá, en el mejor de los casos, demostrar la existencia histórica de tal o tal persona, podrá tal vez certificar la existencia con una probabilidad que se acerque al cien por ciento; sin embargo, no podemos y no debemos esperar de ella que valide los personajes conceptuales de la Biblia; es decir, que valide el sentido que estos personajes tienen en los textos.

Esta oposición entre verdad histórica y sentido intra-textual no nos debe llevar a condenar a la arqueología bíblica. Al contrario, toda ciencia se define por sus límites, por lo que no puede hacer, y mientras más tenga claras sus fronteras, más precisa y eficiente puede ser dentro de sus límites ${ }^{11}$. Notemos así, por ejemplo, que cuando la física abandona la pregunta "por qué" para limitarse a la pregunta "cómo", es cuando realiza sus avances más espectaculares en la explicación de fenómenos a lo largo del siglo XVII. Igualmente, cuando abandonamos el sueño de conocer a las cosas tales como son para limitarnos a los objetos tales como puede conocerlos el entendimiento humano, la ciencia moderna presenta sus mayores avances. De esta manera, establecer sus límites para una ciencia no es construirse como ciencia pobre, sino al contrario reforzar sus posibilidades y ampliar el nivel de certeza accesible dentro de ciertas fronteras. Según el paradigma maximalista de la arqueología bíblica, muchos creyentes podrían ver en este límite de la arqueología bíblica una razón de abandonar su fe ya que buscan en la arqueología razones de creer, con pruebas de la existencia de tal acontecimiento histórico. Tal vez por esta razón, la crítica de la arqueología bíblica puede ser percibida como una agresión por parte de muchos creyentes. Esto sería un error muy grande, y se debería poder trabajar de forma racional y razonable en arqueología bíblica ya que los maximalistas no deberían olvidar que la fe, en su etimo-

\footnotetext{
${ }^{11}$ Podremos ver en los textos de Descartes en qué medida es un proceso de reducción del objeto de la ciencia moderna que le permitió avanzar de manera tan rápida y eficiente (Descartes, 1984). Y para entender en qué medida esta reducción determina toda una nueva ontología que nos hace pasar de la cosa al objeto, el lector podrá ver el libro clásico de Jean-Luc Marion (Marion, 2008).
} 
logía latina de fides (es decir confianza), supone cierta ignorancia y supone la incertidumbre. Quien supiera que Dios existe o quien habría podido, tal como lo soñaron varios filósofos desde Anselmo a Leibniz, demostrar la existencia de Dios, dejarían de inmediato de creer para saber. Paradójicamente, un acto de fe solo puede existir en un estado epistemológico débil, es decir en un estado que no encuentre raíces racionales que lo garanticen ${ }^{12}$. No tenemos fe de que la tierra gire alrededor del sol, lo sabemos, por lo que no demostramos ninguna confianza incondicional en los astros al afirmar el heliocentrismo. Sabemos calcular sus trayectorias y prever los eclipses. Por lo tanto, nuestro conocimiento elimina todo tipo de confianza en ellos. Al contrario, nuestra fe en Dios necesita, para manifestarse como confianza infinita y no como saber, padecer de cierta incertidumbre. A la diferencia de la apertura incondicional hacia una alteridad que supone la confianza en el caso de la fe, el conocimiento siempre presenta cierta clausura del sujeto sobre sí mismo, aunque sea en el hecho que los objetos del saber siempre son objetos para un sujeto. Así, la crítica epistemológica de la posición maximalista en arqueología bíblica no se presenta bajo ninguna circunstancia como cuestionamiento de la fe ni de la religión; al contrario, al establecer otra vez las fronteras, tal vez permita, como lo vamos a ver ahora, clarificar el estatuto epistemológico de la Biblia y de los textos de manera general en un sistema religioso. Para esto, necesitamos regresar a las raíces judías del cristianismo e interrogar la posición maximalista de la arqueología bíblica desde un punto de vista judío.

\section{TOLDOT: LA BIBLIA COMO LIBRO DE HISTORIA MÁS ALLÁ DE LAS HISTORIAS}

Hemos opuesto más arriba en este trabajo, la descripción de la verdad histórica al relato del sentido que le damos a eventos cuya realidad histórica no importa. Podríamos encontrar aquí una de las posibles oposiciones entre Historia y mitología. Esta oposición de la verdad y del sentido nos permite introducir com- plejidad en nuestro trabajo puesto que ambas nociones juegan un papel muy importante en la arqueología bíblica dado que no hay arqueología bíblica sin alguien (o una teoría) que le dé sentido a los hechos o rastros considerados como verdaderos. Al haber en la arqueología una parte de búsqueda de la ver-

\footnotetext{
12 Para una conceptualización brillante de esta oposición entre el conocimiento que siempre requiere el concepto de Dios creado por la metafísica y la fe en Dios, podremos ver el libro de Jean-Luc Marion (Marion, 2010).
} 
dad y una parte de donación de sentido, bien vemos que esta disciplina se debe pensar al cruce de la Historia y de la mitología. Sin embargo, las relaciones entre Historia y mitología no se deben limitar a lo que nosotros percibimos de ellas ya que lo que solemos entender por "Historia" en las lenguas romances está sumamente determinado por la herencia común del latín y del griego, de la misma manera que lo que sucede para la palabra mitología. Es interesante notar para nuestra problemática que tanto la palabra mitología como la palabra historia provienen del vocabulario griego y están entonces completamente determinadas (aunque sea de manera inconsciente) por el pensamiento griego. Pero el hebreo, lengua en la cual deberíamos leer el pentateuco y darle sentido, proviene de otra herencia, liberada de las determinaciones griegas y romanas, 0 más bien dicho todavía no determinadas por una herencia griega y romana. Por lo tanto, tal vez podamos afirmar que la Biblia es un libro de Historia y no de historias, si es que entendemos por Historia otra cosa que lo que las resonancias griegas nos dejan oír en esta palabra. Esto nos permitirá precisar el estatuto de la Biblia y por lo tanto también el de la arqueología bíblica.

Una de las primeras apariciones de la palabra historia en los textos se en- cuentra en el título de la obra de Heródoto que ocupa para muchos el papel originario de la historiografía. El opus que reúne los nueve libros de su Historia de las guerras médicas se titula efectivamente historia (Heródoto, 2011). Sin embargo, esta palabra en griego se debería o, por lo menos, se podría traducir por investigación o exploración, tal como lo vio perfectamente su traductor francés $^{13}$. Si aceptamos que Historia en este contexto griego signifique investigación o exploración de los hechos, bien vemos que se relaciona de forma fundamental con la intención de relatar los hechos tal como se desarrollaron en la realidad, es decir que se relaciona con la verdad. La preocupación de la adecuación entre eventos intra-textuales y eventos extratextuales se puede legítimamente llamarse preocupación por la verdad. Efectivamente, recordemos aquí que en el ámbito griego, la verdad se define de forma muy precisa como la adecuación de una proposición y de una realidad: "Así [...] similarmente las oraciones son verdaderas según sean las cosas reales." (Aristóteles, 1999, 9, 19a, 166) Esta definición de la verdad como adecuación tiene un impacto directo sobre la definición de la historia que por lo tanto se define como búsqueda de la verdad, en este sentido preciso de adecuación del discurso con los eventos reales, o de lo intratextual y de lo extratextual. En este

\footnotetext{
${ }^{13}$ Notemos que de hecho el último traductor francés de la obra de Heródoto decidió darle como título: L'enquête (es decir, literalmente, la investigación). Cf. (Heródoto, 1985).
} 
sentido deberíamos establecer una frontera epistemológica casi hermética entre historia y mitología usando el criterio de la relación con la realidad de los eventos transcurridos. Cuando la historia se preocupa de los referentes extratextuales y por lo tanto de la verdad, la mitología podría entenderse como pura relación de sentido intratextual, sin necesidad que este sentido tenga alguna referencia extra-textual.

Sin embargo, esta diferencia solo es posible a condición de que aceptemos la definición griega de la verdad y de su impacto sobre la definición de la Historia. Pero, lo que los hebreos entienden por Historia no está enmarcado dentro de los conceptos que acabamos de describir ya que en hebreo historia se dice toldot y que por razones cronológicas obvias, no proviene de la tradición griega. Así, cuando hablamos de Historia en el mundo griego o en el mundo hebreo, hablamos de dos disciplinas radicalmente diferentes, que deben entonces ser analizadas de manera distinta. La Historia tal como la entienden los hebreos, es decir la Historia como Toldot y no como historia proviene de una raíz hebrea que significa "generar" o "produ-

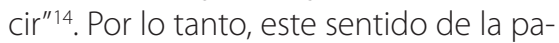
labra Historia no está vinculado con la visión de la Historia como "relato de los eventos" ni con la verdad en su definición griega, sino con la producción de sentido y la dirección que se debe tomar como pueblo judío. Más allá de una adecuación, es un problema de dirección que encontramos en la palabra Toldot. Cuando los judíos nos dicen entonces que la Torah es un libro de Historia, no lo entienden en el sentido griego de historia sino en el sentido hebreo de toldot. Nos es fácil entender esto ya que la Torah nunca pretendió darnos una definición griega del pueblo judío sino una definición judía del pueblo judío. Tomemos dos ejemplos para aclarar este punto de lo que puede ser una versión judía de la Historia en oposición a su versión griega. Esto permitirá aclarar en qué medida y en qué sentido se puede decir que la Biblia es un libro de Historia. Hagámoslo con un ejemplo filológico y con otro que nos lleva al corazón de la arqueología bíblica.

Todos conocemos el texto de Génesis en el cual se relata la creación de la mujer, que es la base de veinte siglos de machismo occidental:

Entonces el Señor Dios hizo caer sobre el hombre un profundo sueño, y cuando este se durmió, tomó una de sus costillas y cerró con carne el lugar vacío. Luego, con la costilla que había

\footnotetext{
14 "[...], le terme utilise par la Bible pour désigner l'Histoire au sens d'historia n'a pas du tout la même racine que cette première série de termes. Il s'agit du mot toldot, qui vient de la même racine que léda, lalédet, naissance, naître, et que l'on traduit généralement par histoire qui n'est que son sens second, toldot signifiant littéralement engendrement. » (Dureau, 2001, 95).
} 
sacado del hombre, el Señor Dios formó una mujer y se la presentó al hombre. El hombre exclamó: «iEsta sí que es hueso de mis huesos y carne de mi carne! Se llamará Mujer, porque ha sido sacada del hombre». Por eso el hombre deja a su padre y a su madre y se une a su mujer, y los dos llegan a ser una sola carne (Génesis, 2, 21-24).

Si aceptamos la concepción griega de lo que significa Historia y de su correlación con cierta visión de la verdad, los judíos nos recuerdan con razón en sus interpretaciones que esto no puede ser una Historia ya que todos vemos y sabemos que la mujer no proviene del hombre sino que tanto hombres como mujeres provienen del útero de las mujeres, más aún cuando sabemos que en hebreo Adam es un plural y que por lo tanto el Adam del cual nos habla la Biblia no es un hombre sino el mismo colectivo humano ${ }^{15}$. Si leemos entonces este texto con los conceptos griegos en la mente, estamos condenados a decir que son textos mitológicos y relegarlos en el campo de la fe de cada uno sin que ninguna ciencia pueda intentar aclararnos estos puntos. Si aceptamos entonces la dicotomía griega entre Historia y mitología, sin duda alguna la Biblia está más cerca de la mitología que de la Historia. Pero si aceptamos leer el texto con el concepto hebreo de Historia, es decir toldot, se aclara el sentido del texto más allá de su realidad factual. Este texto no nos dice la verdad de la relación hombre-mujer sino el sentido de esta relación para los judíos, sentido que es el siguiente. Recordamos que en la Biblia, todo lo que no está creado a partir del hombre está a su disposición: vegetales, animales y mundo inorgánico están a disposición del hombre ya que al no provenir de él han sido creado de cierta forma para él. Sin embargo, al provenir de la misma materia que la del hombre, la mujer goza de la misma dignidad que él frente a Dios y frente a la Creación, es decir frente a lo absoluto. Bien vemos aquí la diferencia entre Historia y toldot, entre producción de verdad y producción de sentido, y podemos medir las consecuencias radicalmente diferentes que tienen estas lecturas en lo que se refiere a la arqueología bíblica. Para los judíos, ya que Génesis nos da la dirección hermenéutica en la cual se desarrolla la humanidad (y no su verdad entendida como adecuación de un discurso y de una realidad extra-textual), podemos preguntarnos la legitimidad de investigaciones arqueológicas al respeto y lo que podrían aportar a esta creación de sentido.

Pero tomemos un ejemplo que generó debates al interior de la misma arqueología bíblica para precisar las consecuencias de la oposición entre historia

\footnotetext{
${ }^{15}$ Para una magistral interpretación filosófica y filológica de la Torah podremos ver el libro de Josy Einsenberg y Armand Abécassis (Einsenberg \& Abécassis, 2004).
} 
y toldot: el caso complicado del Éxodo. Todos conocemos el libro famoso de los arqueólogos Finkelstein y Silberman que produjo un gran debate en la arqueología bíblica (Finkelstein \& Silberman, 2001) y más allá en el mundo académico. Tal como lo preguntan estos dos arqueólogos: ¿sería posible que lo que nos cuenta el segundo libro de la Biblia tenga alguna realidad histórica? Si bien disponemos de rastros arqueológicos -sobre todo pinturas- que nos indican la presencia de semitas en las tierras de Egipto, ¿qué podemos decir del Éxodo como tal? Según piensen los arqueólogos, este éxodo se hubiera producido alrededor del siglo XIII aC ya que aparece el pueblo de Israel en un jeroglífico -y uno soloegipcio. Podemos entonces bien imaginar que la arqueología bíblica apoya de manera muy fuerte la presencia de semitas en el Egipcio antiguo. Sin embargo, esta interpretación se enfrenta a problemas muy complicados a la hora de evaluar la realidad del Éxodo como tal. Efectivamente, tal como lo señala el libro de Finkelstein y Silberman, ¿cómo imaginar que una presencia de casi cuarenta años en el desierto del Sinaí, presencia de centenas de miles (600 000) de personas, no haya dejado ni el mínimo rastro que podamos encontrar hoy en día? Si tomamos a la arqueología bíblica en serio cuando nos aporta rastros a favor de la historicidad de la Biblia, también debemos tomarla en serio cuando pone en peligro esta misma his- toricidad. Y en lo que se refiere al Éxodo, estos dos arqueólogos plantean problemas que cuestionan a la Biblia como historia en su sentido griego. ¿Cómo imaginar que la huida de 600000 personas de un imperio que contaba con 3 millones de ciudadanos no haya producido consecuencias tremendas en el mismo imperio egipcio? Si Éxodo fuese un relato histórico en el sentido griego de la Historia, deberíamos encontrar rastros de este en el desierto del Sinaí, así como en las consecuencias que hubiera producido en el mismo imperio egipcio. Sin embargo, no encontramos ni lo uno ni lo otro. Notemos además que en este caso no podemos ni siquiera invocar un problema de cronología para salvar la historicidad griega del Éxodo, ya que cualquiera que sea el siglo en el cual se haya producido este éxodo, hubiera tenido que dejar algún rastro sobre el recorrido de las centenas de miles de hebreos y hubiera tenido que tener un impacto muy fuerte en el imperio egipcio.

Sin embargo, bien vemos una vez más que el cuestionamiento del carácter histórico del Éxodo solo es posible y concebible dentro de cierta concepción de la Historia, la concepción griega. Pero el tomar la perspectiva judía sobre el concepto de historicidad de la Biblia nos puede ayudar a avanzar en nuestras interpretaciones y precisar lo que se puede esperar de la arqueología bíblica. Es notable que si bien el libro de Finkels- 
tein y Silberman tuvo repercusiones fuertes en la arqueología bíblica y en la política que la utiliza, no tuvo casi ningún impacto en lo que se refiere a la teología judía. A pesar de los múltiples debates políticos, ningún rabino se escandalizó de la tesis defendida por este libro. Los rabinos, con su silencio, nos ayudan a entender cuál es el estatuto histórico de la Biblia para los judíos y lo que nos quieren decir cuando nos dicen que la Biblia es un libro de Historia. Los rabinos nos ayudan a entender en qué medida el relato del Éxodo tiene una función interpretativa según lo que requiere el concepto de Historia pensado como toldot, fuera de la tradición griega. Efectivamente, para los rabinos del Talmud, la función del Éxodo es la de hacernos entender cómo pasamos del hebraísmo al judaísmo (Abécassis, 2003) y por lo tanto el explicarnos como el judaísmo se presenta como relevo del hebraísmo, podríamos casi decir como Aufhebung del hebraísmo si aceptamos con Derrida que Aufhebung se debería traducir por relevo. Podemos entonces leer al Éxodo como toldot del pueblo judío (Historia como generación del pueblo judío), ha- ciéndonos entender que el pueblo judío únicamente puede liberarse de las leyes humanas que le oprimen (las leyes egipcias de faraón) si se somete a las leyes divinas reveladas en el Sinaí. De esta manera, el Éxodo no nos dice la verdad del pueblo judío (verdad entendida como adecuación de un discurso con una realidad) sino su sentido: el pueblo judío es un pueblo que solo puede existir mientras se somete a los mandamientos de Dios. De hecho, es notable para esta interpretación que en el judaísmo nada es sagrado de por sí: ni instrumentos, ni palabras, ni gestos, ni siquiera una tierra. Lo sagrado solo puede ser tal si el uso que se hace de él respeta las leyes divinas. Así, la arqueología bíblica que se focaliza sobre los rastros del Éxodo no podría, por definición, ni confirmar ni infirmar este, ya que se trata de sentido y no de la verdad del pueblo judío, de toldot y no de historia. El Éxodo nos daría entonces mucho más el sentido que la verdad del pueblo judío que es un pueblo que solo puede existir como pueblo judío en cuanto aplica, esté en donde esté, las leyes divinas que lo definen como pueblo.

\section{CONCLUSIÓN}

Podemos entonces imaginar, gracias a esta articulación de historia y to-dot, que coexisten en la Biblia y en los textos sagrados dos capas de interpretación articuladas como un palimpsesto hermenéutico ${ }^{16}$, lo cual nos permite pre-

${ }^{16}$ En este sentido, no es totalmente un azar, que uno de los más grandes filósofos judíos del siglo XX, Emmanuel Levinas, describa a su propia filosofía como un palimpsesto que se articula entre Atenas y Jerusalén: "La pre- 
cisar lo que podemos esperar de la arqueología bíblica. Algunos puntos de la Biblia sin duda plantean el marco histórico dentro del cual se desarrollan los eventos importantes, y este marco puede y debe ser estudiado por los arqueólogos para revelarnos el contexto preciso en el cual fueron redactados los textos. Así, la presencia de semitas en Egipto parece incontrastable, asimismo la crucifixión de un judío llamado leshoua en la parte oriental del imperio romano, en una región bajo la responsabilidad de un tal Pilates ${ }^{17}$. Sin embargo, más allá de la interpretación histórica de muchos eventos, podemos pensar con los rabinos que existen en la Biblia algunos textos cuyo único objetivo es el de darnos el sentido de la aventura humana más que su verdad; así, por ejemplo, el del Éxodo o el del Génesis. En estos casos la arqueología bíblica no nos es de ninguna ayuda para poder entender los textos ya que va más allá de sus capacidades epistemológicas.

Sin embargo ya que no podemos hacer a priori la diferencia entre estos dos tipos de texto (los que apuntan a la verdad y los que apuntan al sentido), el gran valor de la arqueología bíblica tal vez sea el de poder aclarar este punto, y el permitirnos distinguir entre los textos que se deben leer según la concepción griega de la Historia, de los textos que debemos interpretar según la concepción hebrea de toldot. Así al limitar el campo de investigación de la arqueología bíblica y sus pretensiones (sobre todo las de los defensores de la posición maximalista en arqueología bíblica que esperan encontrar en ella una confirmación y una justificación de su fe), ampliamos en realidad sus horizontes ya que más allá de su propia especificidad arqueológica, podemos hacer de ella una meta-ciencia que nos permite distinguir los textos que deben ser leídos con los ojos del historiador de los textos que deben ser interpretados con los ojos del creyente. Su valor no se limita entonces a aumentar nuestros conocimientos en arqueología ya que gracias a ellos encuentra un valor para los filósofos, los teólogos, antropólogos y cualquier ser humano que quiera encontrar posibles salidas del laberinto hermenéutico que representa la Biblia.

gunta tiene un alcance más general: las sagradas escrituras leídas y comentadas, en Occidente, ¿han inclinado la escritura griega de los filósofos o sólo están unidas a ellos teratológicamente? ¿Filosofar es descifrar en un palimpsesto una escritura oculta? " (Levinas, 2009, 129). Para una interpretación de la filosofía como palimpsesto en Levinas podremos ver el estudio de Benny Levy (Levy, 2009).

${ }^{17}$ Escribimos aquí "un tal Pilates" sin desprecio ninguno, solo queremos marcar que la arqueología bíblica no nos puede demostrar (ya que no entra dentro de sus competencias) que el Pilates histórico es el Pilates bíblico, ya que si la primera nos revela su verdad, la segunda solo se ocupa de su sentido. 


\section{BIBLIOGRAFÍA}

Abécassis, A. (2003). L'univers hébraïque-Du monde païen à l'humanisme biblique. Paris : Albin Michel.

Aristóteles (1999). De Interpretatione. Madrid: Tecnos.

Corbo, V. (1968). The house of St. Peter at Capharnaum: a preliminary report of the first two campaigns of excavations, April 16-June 19, Sept. 12-Nov. 26, Franciscan Print Press.

Deleuze, G. \& Guattari, F. (1991). Qu'est-ce que la philosophie? (2a. ed.). Paris: Editions de Minuit.

Descartes, R. (1984). Reglas para la dirección del espíritu. Madrid: Alianza.

Dureau, Y. (2001). Histoire des hommes et histoire divine dans l'œuvre de Shakespeare, Etude de deux pièces. En M. Viallon-Schoneveld (Ed.). L'Histoire et les historiens au XVIIe siècle (pp. 95-108). Saint Etienne : Publications de I'Université de Saint Etienne.

Einsenberg, J. \& Abécassis, A. (2004). Bible ouverte. Paris : Albin Michel.

Finkelstein, I. \& Silberman, N. (2001). The Bible Unearthed:Archaeology's New Vision of Ancient Israel and the Origin of Its Sacred Texts. New York: Free Press.

Girard, R. (1972). La violence et le sacré. Paris : Grasset.

Heródoto. (1985). L'enquête, traducción francesa de Andrée Barguet. Paris : Folio classique.

Heródoto. (2011). Los nueve libros de la Historia. Madrid: Ediciones Edaf.

Josefo, F. (1997). Antiguedades Judias. Madrid: Ediciones Akal.

Kuhn, T. (1962). The structure of scientific revolutions. Chicago: University of Chicago Press.

Lévi-Strauss, C. (2009). Mythologiques. Paris: Plon.

Levinas, E. (2009). El humanismo del otro hombre. Madrid: Siglo Veintiuno Editores.

Levy, B. (2009). Lévinas: Dieu et la philosophie, Séminaire de Jérusalem, 27 novembre 1996 - 9 juillet 1997. Paris : Verdier.

Marion, J-L. (2008). Sobre la ontología gris de Descartes. Madrid: Escolar y mayor. 
Marion, J-L. (2010). Dios sin el ser. Vilaboa: Ellago ediciones.

Mazar, E. (2008). Preliminary Report on The City of David Excavations 2005 at the Visitors Center Area. Jerusalén: Shalem Press.

Merz, A. \& Tieleman, T. (2008). The letter of Mara Bar Serapion: some comments on its philosophical and historical context. En A. Houtman (Ed.). Empsychoi Logoi. Religious Innovations in Antiquity. Studies in Honour of Pieter Willem van der Horst (pp. 107-134). Leiden: Brill.

Polibio. (2008). Historia de Roma. Madrid: Alianza Editorial.

Romilly, J. (1995). Alcibiade, les dangers de l'ambition. Paris : Fallois.

Sneh, A., Weinberger, R., Shalev, E. (2010). The Why, How, and When of the Siloam Tunnel Reevaluated. Bulletin of the American Schools of Oriental Research (359), 57-65.

Tucídices. (2005). Historia de la Guerra del Peloponeso. Madrid: Ediciones Cátedra.

Tuland, C. (1967). ZB in Nehemiah 3: 8 , A reconsideration of Maximalist and Minimalist Views. University Seminar Series, (5), 158-180.
Vlastos, G. (1991). Socrates, Ironist and Moral Philosopher. Cambridge: Cambridge University Press.

Van Voorst, R. (2000). Jesus outside the New Testament, an introduction to the ancient evidence. Cambridge: Eerdmans Publishing.

Woolley, L. (1929). Ur of the Chaldees. London: Ernest Benn Limited. 